\title{
DYNAMISM PATTERNS OF WESTERN MEDITERRANEAN CRUISE PORTS AND THE COOPETITION RELATIONSHIPS BETWEEN MAJOR CRUISE PORTS
}

\author{
Jeronimo Esteve-Perez \\ Universidad Politécnica de Cartagena, Department of Naval Technology, Spain \\ Antonio Garcia-Sanchez \\ Universidad Politécnica de Cartagena, Department of Economics, Spain
}

\begin{abstract}
The Mediterranean Sea has seen an increase of ports hosting cruise ships during the first fifteen years of the 21st century. The increase in cruise ship presence in Mediterranean ports is associated with the dynamism of cruise traffic in recent years, with an average annual growth of 7.45\% for cruise passengers worldwide during the period of 1990-2015. Cruise traffic is a maritime business that is primarily composed of two elements, maritime affairs and tourism. This article focuses on the maritime component. With the growth of the cruise industry, cruise lines have been forced to seek new ports to meet demand in an attempt to create differentiated products based on the ports that compose the itinerary. The itinerary system of cruise traffic makes the cruise ports depend on one another to design an itinerary. This feature results in both complex geographic relationships in the design of a cruise itinerary and complex competitive/cooperative relationships between ports. The aim of this article is to present the hierarchic picture of a sample of 29 cruise ports in the Western Mediterranean region during the period of 2000-2015. To achieve this goal, a port size classification is proposed and a shift-share analysis at the inter-and intra-group size level is applied. Moreover, concentration measures are used to determine the changes in the levels of market concentration. Furthermore, a dynamic model is proposed to determine the competitive or cooperative relationships between cruise ports. The proposed model is applied to the largest ports with data from the 2001-2015 period.
\end{abstract}

Keywords: cruise ports; Mediterranean ports; hierarchic patterns; coopetition; shift-share analysis

\section{INTRODUCTION}

Between the 1990s and 2015, the cruise industry exhibited extremely dynamic behaviour and high growth rates. In 2015, approximately 23 million people vacationed on cruise ships [4]. This figure is more than threefold higher than the number in 2000 (7.2 million passengers), and sixfold higher than in 1990 (3.8 million passengers). Moreover, the forecasts are positive - an average annual growth rate of $3.3 \%$ is expected for the period of 2016-2019 [5]. While the global financial crisis of 2008-09 had a major impact on maritime cargo shipping, for example, in 2009, the global containerised cargo rate fell by $9.0 \%$ compared to 2008 , whereas worldwide cruise passengers grew by $9.1 \%$ [26]. Cruise lines and cruise ports continued experiencing steadily rising numbers of passengers.

The cruise industry is composed of two overall components: maritime affairs and tourism. The maritime component is represented by cruise ships and cruise ports. Cruise ships have a dual function - the function of the vast majority of vessels, shipping, and as an accommodation and entertainment facility with a sophisticated design, which leads to their description as floating hotels and marine resorts. Cruise ports are a key element in drawing up an itinerary as they connect the ship and tourist destinations. With the growth of the cruise industry, cruise ports have been increasing in importance. The tourism component is composed of the leisure and entertainment facilities on board cruise ships 
and the tourist hinterland of each port of call that passengers visit on cruises.

The vast majority of research studies on the cruise industry thus far have focused on the tourism component. However, in recent years, this trend has changed. Research studies associated with the maritime component of the cruise industry have increased, focusing mainly on cruise ports. Some of these studies include the following themes: relevant factors in the site selection of cruise terminals [9], the cruise industry's selection criteria for being a homeport $[10,1]$, the incentive mechanism in concession agreements for cruise terminal activities [27] and determinants of cruise traffic that is registered by a port $[3,6]$. This paper focuses on the maritime component of the cruise industry, specifically on cruise ports.

The core element of the cruise industry is its itinerary system, which involves selling a set of ports and destinations that comprise the itinerary rather than a single destination or port. In 2015, three cruise regions accounted for $67 \%$ of the deployed capacity. The Caribbean was the main region, with a share of $36 \%$, followed by the Mediterranean and Northern Europe, with $20 \%$ and $11 \%$ of the deployed capacity, respectively. In the period 2004-2014, Europe was the driving force for cruising: the total number of passengers increased by $136.2 \%$ as further interest in cruises in the region provided the incentive for cruise lines to create more itineraries throughout the continent, especially in the Mediterranean Sea [19]. During the first 15 years of the 21 st century, the Mediterranean was the most dynamic region, with an average annual growth rate of $9.4 \%$. The Western Mediterranean had the largest cruising activity, with $70 \%$ of cruise passenger movements occurring during the period of 2000-2015 [13, 16]. In this section of the Mediterranean Sea are the tourist powerhouses of Italy and Spain with the highest and second highest cruising activity, respectively, in the Mediterranean basin.

With the growth in the cruise business, cruise lines have had to seek new ports to meet demand and satisfy first-time cruise passengers and repeat cruise passengers by attempting to offer differentiated products based on the ports that comprise the itinerary. This article analyses a sample of 29 Western Mediterranean ports in seven countries. The purposes of the article are as follows: (a) to determine patterns of change in the cruise traffic of the ports in the sample during the period of 2000-2015, (b) to sort the destinations by port size to identify the distribution of the observed evolution and to identify the size with the best results in cruise activity, and (c) to determine the cooperative/competitive relationships among the largest ports that combine homeport passenger movements and transit passenger movements. The main contributions of this study, from a cruise itinerary viewpoint, are as follows: (1) an analysis of a sample of ports belonging to seven countries, (2) the presentation of a model to determine the cooperative/competitive relationships between cruise ports, and (3) the identification of the best group sizes and the relationships with other ports to offer better information to cruise port managers that would be useful for developing future strategies for cruise business.
The remainder of the paper is structured as follows. Section 2 is devoted to a literature review of cruise ports, spatial dependence in the configuration of a cruise itinerary and the concept of coopetition. Section 3 presents the analysis methodology. In section 4 , the main results and its discussion are presented. Section 5 concludes the paper.

\section{LITERATURE REVIEW}

In cruise shipping, the port is very important for all stages of the cruise ship operation. Ports serve as bases for embarkation and debarkation - homeports - but they also serve as intermediate destinations - ports of call for shore excursions and resupply along the cruise route [12]. In designing an itinerary, first, the cruise line selects the destination region. The next step involves selecting the homeport(s), depending on whether the itinerary is open or closed, from which the itinerary will be developed. Closed itineraries only have one homeport because the itinerary starts and ends at this port; in this case, the itinerary is a closed loop. Open itineraries have two homeports - the itinerary starts and ends at different ports. Ports of call are then needed to complete the itinerary. According to Marti [11], the geographic concepts of 'site' and 'situation' can contribute to a better understanding of the cruise-ship port selection process. 'Site', a physical factor, is obviously of great significance to the origin and evolution of cruise ports. 'Situation' can comprise either physical or cultural qualities. The location of embarkation ports relative to destination ports in addition to vessel speed and the number of days allocated to complete each round-trip voyage also governs the number of ports that can be visited [11].

In a set of ports of call, there may be a mix of 'must-see' ports/marquee ports and discovery ports; each type differs according to the tourism attractiveness of the port. 'Mustsee' locations/marquee ports are world-famous ports that are absolutely necessary for every itinerary. A discovery port is one that is not world-famous but offers the sense of discovering an unknown treasure [22]. In addition, some discovery ports feature technical calls to obtain a balance between sailing time and shore time, especially between two 'must-see' port calls. Some ports - homeport or ports of calls - are marquee destinations. The concept of marquee destinations is related to tourist attractions located outside the port city and is linked to the port - for example, Civitavecchia (Rome), Livorno (Florence, Pisa) or Motril (Granada). 'Must-see' locations/ marquee ports/destinations underline that the concept of itineraries is still bound to the concept of the destination and that itineraries can be more effectively sold if they include some specific destinations [21] because these destinations attract passengers and generate the most sales for the cruise itinerary.

The decision for a cruise line to call at a specific port or, more importantly, to establish a homeport for their vessels depends on whether the area in which the port is located is attractive for cruise itineraries. A port cannot be attractive 
if it is not located close to or in an area where there are other available cruise ports with which to design an itinerary. Thus, a cruise port needs to be located close to or within an area where cruise ships operate [12]. The above geographic constraint can be referred to as a geographic constraint at the global level in terms of designing an itinerary, but there is also a strong spatial dependence on the configuration of a cruise itinerary within the cruise destination region or the specific sector of a cruise destination. This geographical dependence results in a negative spatial relationship with the range of short distances between ports, which becomes positive at intermediate distances and negative again at large distances [7]. Cruise ports need one another to survive according to a 'mutual benefit' principle [1]. Additionally, the optimisation of sailing distances in designing an itinerary is a key question because fuel costs have a major impact on the total shipping costs because fuel consumption has an exponential dependence on sailing speed.

The presence of sufficient port-specific and port-related infrastructures, the absence of intense use that may lead to congestion and process disruption, and the modernisation of infrastructures and processes to provide efficient and effective port services are key to including a port as part of an itinerary. While principal cruise ports serve derived demand, their own competitiveness is, to a certain degree, a draw for attracting cruise calls. In seeking to develop a new product, cruise lines have added and continue to search for new cruise ports to add to itineraries and attract land-based holidaymakers or cruises that wish to return [19]. Rodrigue and Notteboom [21] note that the cruise industry works in a 'supply push mechanism' as cruise lines aim to generate demand for cruises by providing new products (itineraries) with a larger and more diversified range of ships. Therefore, the cruise industry continually needs to introduce new itineraries and ships with new amenities and destinations as well as redeploying older and smaller vessels on other itineraries [1]. Furthermore, cruise lines wish to create itineraries that include ports of different sizes, as each type of port provides different types of experiences by blending different types of attractiveness and permitting future passengers to select from among various options to access the departing port [19]. In addition, cruise lines in the process to seek new destinations keep in mind the geopolitical factors and institutional stability of the cruise destination and, also, the security level of ports and tourist hinterlands in order to provide 'secure-comfortable' itineraries. These factors influence both the sustained development of a cruise destination and the success of a particular itinerary.

Strong growth in Mediterranean cruises in the past several years has increased congestion at several ports, both on the maritime side (piers) and on the land side (adjacent touristic districts). This may create constraints in the establishment of itineraries because only a limited number of slots to visit ports of call may be available; adding ports of call may require additional costs and even a bidding process to guarantee access [21]. The possibility of being included in itineraries that involve several ports is a vital parameter, particularly for the development of a non-marquee cruise port [19].
Cruise ports compete within the limits of certain geographic regions. These limits are mainly shaped according to the location of the regional homeports [1]. There is an interdependent relationship between cruise ports; it is necessary to see these ports of call from the point of view of the itineraries as a whole rather than as isolated destinations. This then leads to complex relationships between the cruise ports. Competition and cooperation simultaneously occur between two or more rival ports in a given market. The competition is more intense between ports of the same category [19]. In the case of cruising, the close relationship that is necessary between ports to create attractive itineraries can be described as the perfect case of 'coopetition'. Branderburger and Nalebuff [2] defined 'coopetition' as a mix of the verbs 'cooperation' and 'competition' to describe the 'win-win' strategy used by ports that are very close to one another and must cooperate and compete simultaneously for a sustainable market share. Furthermore, according to Song [24], cooperation is an action by which ports work together to further the general interest of all ports and in which ports increase their market power through collaboration.

This phenomenon has long been observed in cargo ports, especially container ports. Song [23] states that 'coopetition' is a way of collaborating to compete. Such collaboration may prevent mutually destructive competition between players. A strategic alliance can strengthen both partners against outsiders even if it weakens partner individually [8]. Furthermore, a collaborative strategy is more additive than a competitive strategy. Interfirm 'coopetition' is highly compatible, and mutually beneficial strategies with different objectives can be strengthened when players work together. This approach can be applied in the configuration of a cruise itinerary with ports of different sizes, technical features and tourist attractiveness. Furthermore, port coopetition results in stronger bargaining powers against governmentmandated trade, investment barriers, mega-carriers and shipping alliances [23]. Bearing this background in mind, the methodology for classifying the ports in the sample according to size is presented next to analyse the evolution of cruise traffic in these ports and the proposed cooperation/ competition dynamic model.

\section{METHODOLOGY}

The criterion used to select the ports in the sample is the registration of more than 7500 average total cruise passenger movements per year between 2000 and 2015; 29 ports meet this criterion. Regarding the cruise activity in the Western Mediterranean Sea, 48 ports in 2015 registered cruise passenger movements [16]. The criterion chosen to classify ports by size is associated with the annual cruise passenger movements. In the literature, one can find the following classification structures according to size. MedCruise used a classification that is divided in two categories, Category $A$ and Category B. Category $A$ is composed of ports with traffic from more than 130,000 cruise passengers in 2013, 
more than 80,000 cruise passengers in 2014 and more than 100,000 cruise passengers in 2015. Category $B$ is composed of ports with traffic from less than 130,000 cruise passengers in 2013, less than 80,000 cruise passengers in 2014 and less than 100,000 cruise passengers in 2015 [14, 15, 16]. Rodriguez et al. [22] proposed a classification that is divided into five sizes: 'small' (less than 100,000 passenger movements/year), 'medium' (100,000 to less than 250,000 passenger movements/ year), 'large' (250,000 to less than 500,000 passenger movements/year), 'very large' $(500,000$ to 1 million passenger movements/year), and 'huge' (more than 1 million passenger movements/year). Furthermore, Pallis [19] applied a similar classification to the latter that was structured based on five sizes and with the same cruise passenger movements for each size; the difference lies in the name of the largest size, 'major'. The classification proposed in this paper follows an approach similar to the latter two, which is structured as follows. 'Small' (less than 100,000 passenger movements/ year), 'medium' (100,000 to 500,000 passenger movements/year), and 'major' (more than 500,000 passenger movements/year).

Once the 29 ports of the sample are classified by size, the next step of the analysis consists of carrying out a shiftshare analysis to determine the changes in cruise passenger movements that are registered at the intergroup and intragroup level. This analysis is performed to identify the size with the best results and, within each size group, the individual behaviour of each port.

Shift-share analyses have been used extensively to analyse the differences between regional and national growth rates in variables such as export growth, employment and productivity [28]. The 'share' effect reflects the expected growth of cruise passenger movements in a seaport if it were to simply maintain its market share and, as a consequence, evolves in the same way as the port size group as a whole (the same growth rate as the groups). The total 'shift' reflects the total number of cruise passenger movements that a port has actually lost to or won from competing ports in the same port size group, with the expected cruise passenger movements (share effect) as a reference. The sum of the shift effects of all ports/size groups considered equals zero. The components of the shift-share analysis can be calculated with the following expressions:

$$
\begin{aligned}
& A B S G R_{i}=C R U P A X_{i t_{1}}-C R U P A X_{i t_{0}} \\
& =S_{H A R E_{i}}+\text { SHIFT }_{i} \\
& \operatorname{SHARE}_{i}=\left(\frac{\sum_{i=1}^{n} \operatorname{CRUPAX}_{i t_{1}}}{\sum_{i=1}^{n} \operatorname{CRUPAX}_{i t_{0}}}-1\right) C R U P A X_{i t_{0}} \\
& \operatorname{SHIFT}_{i}= \\
& \operatorname{CRUPAX}_{i t_{1}}-\frac{\sum_{i=1}^{n} C R U P A X_{i t_{1}}}{\sum_{i=1}^{n} C R U P A X_{i t_{0}}} \cdot \operatorname{CRUPAX}_{i t_{0}}
\end{aligned}
$$

where $A B S G R_{i}$ is the absolute growth of cruise passenger movements in port $i$ for the period $t_{0}-t_{1}, S H A R E_{i}$ is the shareeffect of port $i$ for the period $t_{0}-t_{1}$ that is expressed in cruise passenger movements, SHIFT $_{i}$ is the total shift of port $i$ for the period $t_{0}-t_{1}$ that is expressed in cruise passenger movements, CRUPAX $_{i}$ is the cruise passenger movements of port $i$, and $n$ is the number of ports in each size group.

Next, two measures of market concentration are applied to calculate the distribution of the changes in cruise traffic in the sample of Western Mediterranean ports. Furthermore, the aim of the concentration analysis aims to determine whether the gain or loss obtained in the shift-share changes the concentration of the Western Mediterranean cruise port market. The measure is applied to the whole sample. The Herfindahl-Hirschman Index (HHI) and Gini coefficient (G) are used. The HHI is useful for identifying the degree of concentration within a port system [18]. The HHI is calculated as

$$
H H I=\sum_{i=1}^{N} S_{i}^{2},
$$

where $H H I$ is the concentration index for the cruise port sample, $S_{i}$ is the market share for port $i$ of the port sample and $N$ is the number of ports in port sample. If the total traffic structure is completely dominated by one specific cruise port, the index has a maximum value of one (full concentration). If, on the other hand, the traffic structure within the port sample is equally divided among all cruise ports such that no seaport dominance exists, the index equals its minimum value of $1 / n$.

The Gini coefficient is a widely used index that measures the percentage departure from a perfectly uniform distribution [18]. The G coefficient is calculated as follows,

$$
G=1+\frac{1}{N}-\frac{2}{N^{2} \bar{Y}}\left(Y_{1}+2 Y_{2}+\ldots+n Y_{n}\right)
$$

where $N$ is the number of cruise market share observations (i.e., number of ports); is the arithmetic mean of the market share; and are the market share numbers in decreasing order. If all the ports in the port sample have the same market share, the Gini coefficient will equal zero. In the event that one port accounts for the total cruise market share (full concentration), the Gini coefficient equals unity.

The last step of the analysis consists of establishing a dynamic model to determine the cooperative/competitive relationships between the ports of the size with the best results that have both homeport passengers and transit passengers. The application of the model aims to determine the type of relationship that prevails between the best sized ports. The calculation premise used to formulate the dynamic model assumes that the market shares of the ports are interrelated, i.e., that there is a linear relationship between the market shares registered by the ports. This calculation premise is made because there is high spatial interdependence between ports in 
designing cruise itineraries and because ports depend on each other; the product offered by the cruise industry is the entire itinerary and not just a single port or destination. Therefore, the market share of each port is selected as a dynamic variable. Similar approaches are applied in cooperative/competitive dynamic models for container ports that share the same hinterland [25]. The model is as follows:

$$
\frac{d x}{d t}=A^{\prime} x \quad x(0)=x_{0}
$$

where $t$ is time, $x$ is the vector of market shares, is the system matrix for identification, and $x_{0}$ is the vector of the initial values. By applying simple difference approximations for the derivatives obtained, for each time step $\Delta t$, the following relationships are calculated:

$$
b_{n}=A x_{n} \quad b_{n} \equiv x_{n+1}-x_{n} \quad A \equiv \Delta t A^{\prime} .
$$

The model can be reformulated as

$$
b_{n}=X_{n} a \text {. }
$$

Next, if the observed market shares are taken as the solution, then an overdetermined system, Eq. (9), is obtained, which may be solved by the least-square method. The sum of the squares of the errors should be minimal; see Eqs. (10) and (11).

$$
\begin{aligned}
& a_{11} x_{1}+a_{12} x_{2}+\cdots+a_{1 n} x_{n}=b_{1} \\
& \begin{array}{llll}
\vdots & \vdots & \ldots & \vdots
\end{array} \\
& a_{m 1} x_{1}+a_{m 2} x_{2}+\cdots+a_{m n} x_{n}=b_{m}
\end{aligned}
$$

where $m$ and $n$ are the sub-indices of the interrelated ports.

$$
\begin{gathered}
\|A x-b\|_{2}=\min . \\
\|A x-b\|_{2}^{2}=(A x-b)^{T}(A x-b)= \\
x^{T} A^{T} A x-2 x^{T} A^{T} b+b^{T} b .
\end{gathered}
$$

Minimization yields a system of equations,

$$
A^{T} A x=A^{T} b,
$$

from which $a$ can be calculated. The model proposed is tested with the market shares of ports of the best size that combine both homeport passenger movements and transit passenger movements in the period of 2001-2015. Only off-diagonal coefficients are interpreted; the interpretation criterion is ports that are connected by a positive coefficient as cooperative and ports connected by a negative coefficient as competitive.

\section{RESULTS AND DISCUSSION}

The application of the proposed classification in three size categories, which is partially based on Rodrigue et al. [22] and Pallis [19], as mentioned in the methodology section, to the sample of the ports yields the following results. The 'medium' group is the largest, with 14 ports in seven countries: Cádiz, Cannes-Antibes, Gibraltar, Ibiza, La Goulette, La Spezia, Málaga, Messina, Monaco, Palermo, Toulon, Valencia, Valletta and Villefranche. This is followed by the 'major' group, with eight ports in three countries: Barcelona, Civitavecchia, Genoa, Livorno, Marseille, Naples, Palma de Mallorca and Savona. The remaining seven ports of the sample are encompassed in the 'small' group: Alicante, Almería, Cagliari, Cartagena, Mahón, Motril and Nice.

The first stage of the shift-share analysis consisted of an intergroup analysis by size group. The net result for the whole period of 2001-2015 yields 'major' ports as the best size, with a positive shift of 659,019 passenger movements. This gain has been at the expense of 'medium' and 'small' ports because both saw a negative shift over the period. The former saw a decrease of 568,718 passenger movements and the latter a decrease of 90,301 passenger movements. The general trend throughout the period was that the year in which the 'major' ports won passenger movements was when 'medium' ports lost movements and vice versa; see Figure 1.

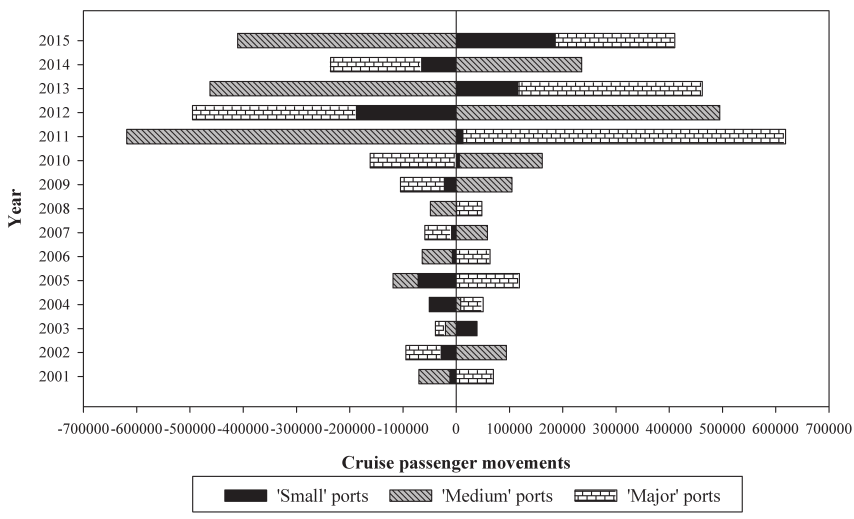

Fig. 1. Shift analysis for three size groups for Western Mediterranean cruise ports

The second stage of the shift-share analysis consisted of an intragroup analysis to determine the behavioural pattern of each port within the group. Among 'major' ports, Marseille had the greatest gain; see Figure 2. This gain is the picture of the growth in the French source market, in which the number of French cruise passengers in 2015 was approximately three times the number registered in 2003. In addition, the creation of French brands/cruise lines - such as Croisières de France (CDF), which belongs to the Royal Caribbean Cruises Limited group - is also influential. Furthermore, Marseille is the main gateway to Mediterranean itineraries for the French 
source market. Source markets, whenever possible, prefer to embark at national ports. Moreover, since 2009, there has been a private terminal operator that is integrated from three cruise lines: Costa Crociere, 40\%; MSC, 40\%; and Louis Cruises, $20 \%$ [27]. According to Esteve-Perez and Garcia-Sanchez [6], the intervention of a private terminal operator has a positive bearing on the number of cruise passengers. In Marseille, this effect has been observed: from 2010, an increase in passenger movements has been registered.

Civitavecchia and Barcelona are also high-ranking ports. Civitavecchia is a gateway port to the must-see destination of Rome. The high tourist attractiveness of this destination makes Civitavecchia one of the attraction poles for cruises in the Western Mediterranean. Moreover, since 2006, there has been an intervention of private terminal operators in Civitavecchia that are integrated three cruise lines, each with a share of 33.33\%: Costa Crociere, RCCL and MSC [27]. Barcelona is a must-see port in the Western Mediterranean with a market share of $14.49 \%$ during the period of 2000 2015 , the highest share in the sample of 29 ports. In addition, since 2000, Barcelona has had private terminal operators for its cruise terminals. This port, coupled with Civitavecchia, constitutes the two main attraction poles for Western Mediterranean itineraries. The success of the two ports can be associated with two concepts: high tourism attractiveness (Barcelona and Rome) and adequate cruise infrastructures that are adapted to the growth of the cruise industry. Barcelona and Civitavecchia are ports that generate greater sales for certain itineraries.

The positive shift from Palma de Mallorca is associated with its 'must-see' port character and its strategic geographical position in the Central Western Mediterranean. The low gains recorded are mainly associated with losses for seven years in a row, from 2003 to 2009, and two years in a row, from 2011 to 2012, switching to wins during 2013-2015.

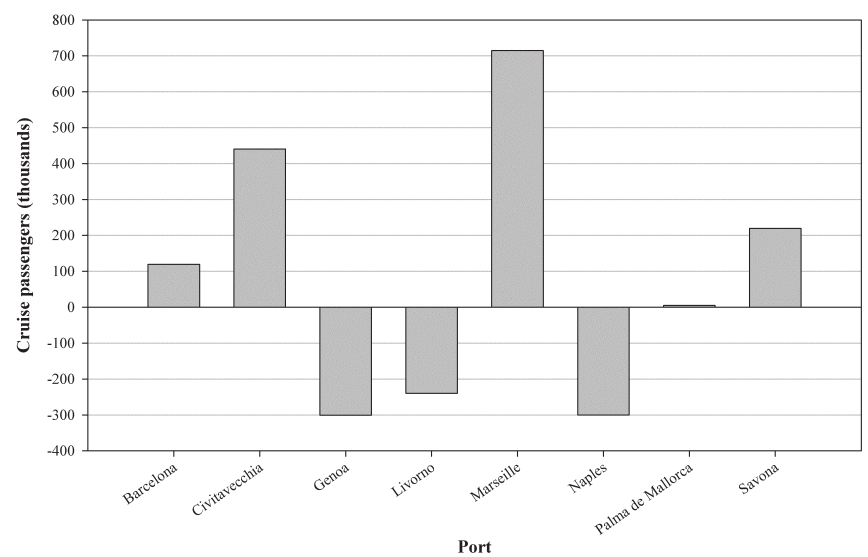

Fig. 2. Intragroup shift analysis for the 'major' group, net results for period 2001-2015

In contrast, the ports of Genoa, Livorno and Naples recorded losses. In both Genoa and Livorno, signs of congestion are seen in the last period of the analysis. In fact, these data are associated with gains from Savona, which serves as an alternative to Genoa due to the short distance that separates them (19 nautical miles).

In the 'medium' group, two behaviour patterns are seen. A set of ten ports is located in the spectrum of a shift of $+/$ 100,000 passenger movements, in which six have losses and the remaining four have wins. The second behaviour pattern is characterised by a shift of higher magnitude; see Figure 3. La Spezia is the port with the largest gain; its geographical proximity to Livorno, coupled with congestion symptoms recorded in Livorno in recent years, make it an alternative to the Livorno dock - hence a noteworthy gain is seen. Valencia is the second port with higher gains. In recent years, there has been an increase in cruise infrastructure in the port of Valencia. The average annual growth of this maritime traffic was $44.55 \%$ during the period of 2000-2015. Valencia also acts as a homeport mainly for the Spaniard source market. More specifically, Valencia acts as a homeport for Spaniards living in the centre of the Iberian Peninsula due to the good connections via high-speed railways and motorways between the centre of Spain and Valencia.

The loss of 846,781 cruise passenger movements in La Goulette is extremely significant. The causes of this loss are associated with the political instability associated with the Arab Spring during 2010 and 2011 and the terrorist attacks in Tunis in March 2015. These events resulted in a remarkable loss of 667,499 passenger movements in 2011 and 420,427 passenger movements in 2015. Villefranche experienced a negative shift of 349,176 cruise passenger movements. The reasons for this loss are associated with the high growth of Marseille and its lack of berthing facilities. The call at Villefranche requires the use of anchoring and tendering services. The trend of increases in the sizes of cruise ships that have been put into service in recent years means that port facilities must adapt to the new generation of megacruise ships.

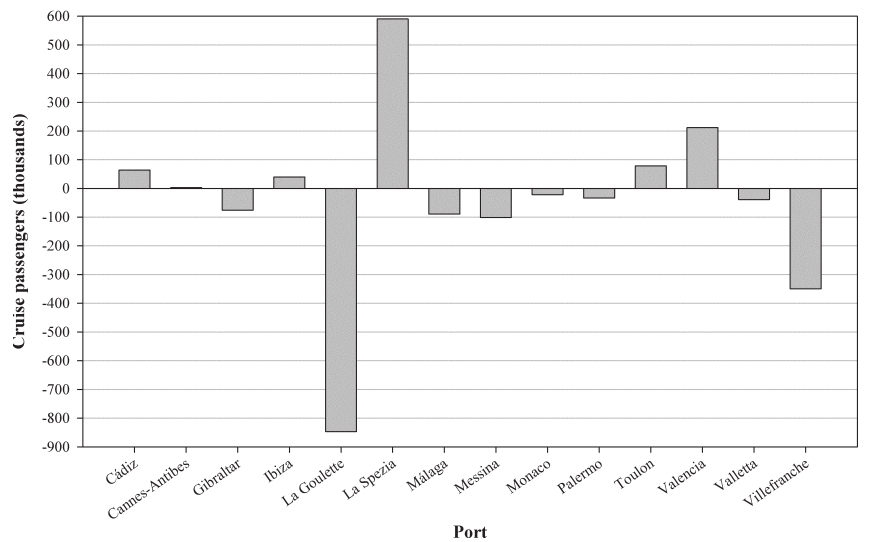

Fig. 3. Intragroup shift analysis for the 'medium' group, net results for period 2001-2015

Regarding 'small' group, only two ports have seen increasing shifts in the period of 2000-2015; see Figure 4. Cagliari has had the highest gains; its growth rate during this period was $36.82 \%$. A partial influence for this gain is the reconfiguration of itineraries that had calls in La Goulette, 
as lots of calls were cancelled after the terrorist attacks in Tunis in 2015 and part of the vessels were redirected to Cagliari. Also, the reconfiguration of these itineraries has mostly benefited Valletta and the ports of Sicily and Sardinia. These changes in the itineraries respond to the search for 'secure-comfortable' calls. Furthermore, in Cagliari, a private terminal operator has been operating since 2012. The company terminal operator is a partnership between RCCL and Venezia Terminal Passeggeri Spa [19]. In 2013 and 2015, Cagliari registered positive net shifts of 61,591 and 175,127 cruise passenger movements, highlighting the positive effect of the intervention of a private terminal operator. Cartagena developed a number of commercial strategies to promote cruise traffic on their docks during the period of 2000-2015, and the sample shows growth of 20.03\% during 2000-2015. In addition, in 2016, the milestone of becoming an interporting port for Princess Cruises was attained.

Nice has seen the highest negative shift of the 'small' group, with a loss of 161,779 cruise passenger movements. Nice can be affected negatively by the growth of Marseille and the technical limitations of its cruise port facilities. The maximum ship dimension per berth in Nice is 210 meters in length; anchorage is also available [17]. The vast majority of contemporary cruise vessels cannot call at this port because the ship lengths are greater than 210 meters. In this particular case, the call would require anchoring and use tendering services.

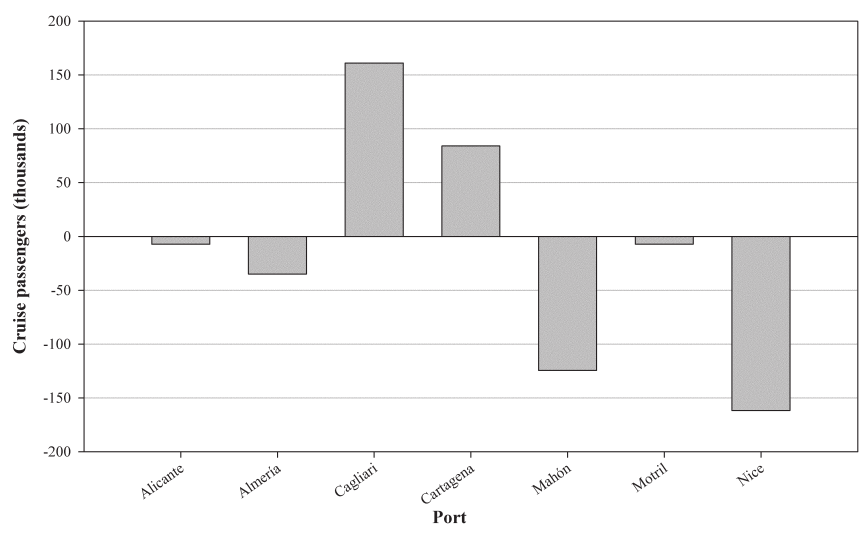

Fig. 4. Intragroup shift analysis for the 'small' group, net results for period 2001-2015

The shift data obtained indicate that the process of win or loss between ports is not based on removing market participants; all ports require one other because the cruise industry sells itineraries rather than single port destinations. In addition, it should be kept in mind that the sample of ports analysed is part of the Western Mediterranean cruise port market. Then, some traffic might have shifted to other ports, like North Corsican ports and North Sardinian ports, that are situated in the Western Mediterranean but are not part of the sample of ports analysed.

Figure 5 shows the Herfindahl-Hirschman indices and Gini coefficient values for the entire sample of ports. The Herfindahl-Hirschman indices for the entire Western Mediterranean are extremely stable over time, with an average value of 0.073 during the period of 2000-2015. Changes in the values of $\mathrm{HHI}$, with an average annual increase of $0.57 \%$, indicate a modest trend towards a less evenly distributed market. Pallis and Arapi [20] obtained similar results for the Western Mediterranean sector by applying HHI to cruise passenger movements that are registered between 2005 and 2014.

The values of the Gini coefficient confirm the conclusions obtained by the HHI regarding the evolution of cruise port market concentrations; see Figure 5. Since 2000, the entire sample of ports has remained virtually at the same level of concentration with minor fluctuations towards concentration, with an average annual change rate of $0.32 \%$.

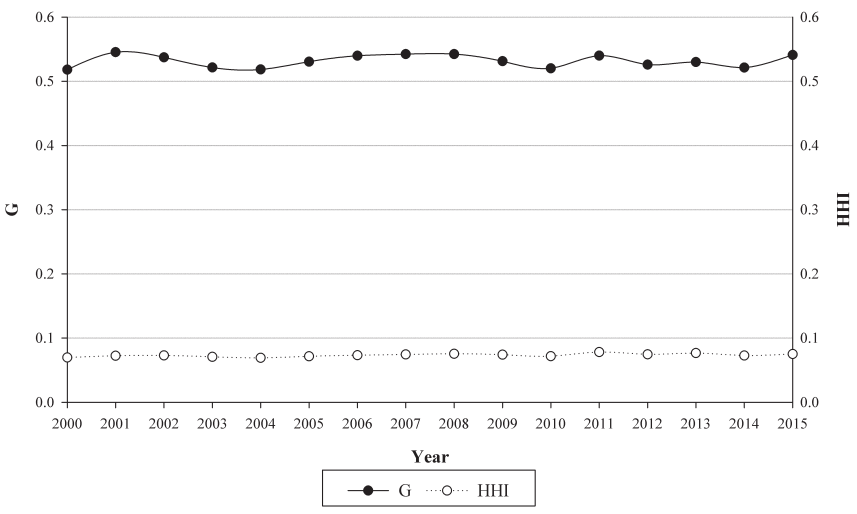

Fig. 5. Values of HHI and G coefficients for the whole sample of ports for period 2000-2015

Among the ports of the 'major' group, six have registered both homeport and transit passenger movements: Barcelona, Civitavecchia, Genoa, Marseille, Palma de Mallorca and Savona. Coopetition can be performed at the inter- and intraitinerary levels, which is why the study of coopetition models focus on ports sharing homeport traffic and transit traffic. Therefore, the dynamic model is created with these six ports while focusing on the three main ports via market share: Barcelona, Civitavecchia and Palma de Mallorca. The first application of the dynamic model only focuses on these three ports because they are must-see ports, gateways to worldfamous tourist destinations, leaders throughout the period in accumulating two-thirds of the market share of 'major' ports that combine homeport and transit traffic, and have more than one million average cruise passenger movements during the period of 2001-2015. The application of the model seeks to determine the type of relationships that predominate among the largest 'major' ports. Particularising the dynamic model proposed in equation (9) with the six ports that comprise the analysis yields the following results.

Barcelona shows high degree of cooperation with the other ports, both for homeport traffic and port-of-call traffic. This result can be interpreted as follows: if the remaining ports experience more cruise traffic, Barcelona hosts more transit ship calls or more itineraries that start and/or end at Barcelona with calls in other ports. Moreover, Barcelona is the main homeport and the second port of call of the six ports under analysis, with an average market share of $31.3 \%$ and 
$25.6 \%$, respectively, during 2001-2015. Thus, it has significant bargaining power to concentrate itineraries in its berths. Barcelona has excellent cruise infrastructures for hosting homeport operations with high numbers of cruise passengers. In addition, these cruise facilities are adapted for megacruise ships. Furthermore, the high tourism attractiveness of Barcelona makes this port one of the favourite calls for cruise lines in attempting to garner greater sales of the itinerary. Transit traffic represented $45.5 \%$ of all cruise traffic registered in Barcelona during 2001-2015.

The results of these calculations for the homeport are shown in Table 1.

Table 2 shows the results with transit cruise passenger movements. traffic. Palma de Mallorca is the second homeport and the third port of call for the six ports under analysis, with a market share of $17.1 \%$ and $17.9 \%$, respectively, during 2001-2015. Palma de Mallorca has competitive homeport relationships with its closest geographically ports, Barcelona and Marseille, because they constitute alternative gateways to itineraries in the northwestern sector of the Western Mediterranean. The share of homeport traffic in Palma de Mallorca is 47.5\%. On the other hand, the growth of transit calls in Barcelona, Marseille, Savona and Genoa benefit Palma de Mallorca because it hosts more transit calls as a result. The competitive relationship with Civitavecchia may be associated with the fact that Palma de Mallorca and Civitavecchia are the most geographically distant (459 nautical miles).

Tab. 1. Cooperative/competitive relationships among the largest 'major' Western Mediterranean ports for the homeport category during the period of 2001-2015

\begin{tabular}{|c|c|c|c|c|c|c|}
\hline & Barcelona & Civitavecchia & Palma de Mallorca & Marseille & Savona & Genoa \\
\hline Barcelona & & $\begin{array}{c}\text { Cooperative } \\
(0.510)\end{array}$ & $\begin{array}{c}\text { Cooperative } \\
(0.353)\end{array}$ & $\begin{array}{c}\text { Cooperative } \\
(0.145)\end{array}$ & $\begin{array}{c}\text { Cooperative } \\
(0.084)\end{array}$ & $\begin{array}{c}\text { Cooperative } \\
(0.314)\end{array}$ \\
\hline Civitavecchia & $\begin{array}{c}\text { Cooperative } \\
(0.083)\end{array}$ & & $\begin{array}{c}\text { Cooperative } \\
(0.089)\end{array}$ & $\begin{array}{c}\text { Cooperative } \\
(0.195)\end{array}$ & $\begin{array}{c}\text { Cooperative } \\
(0.274)\end{array}$ & $\frac{\text { Competitive }}{(-0.054)}$ \\
\hline Palma de Mallorca & $\frac{\text { Competitive }}{(-0.340)}$ & $\begin{array}{c}\text { Cooperative } \\
(0.135)\end{array}$ & & $\frac{\text { Competitive }}{(-0.300)}$ & $\begin{array}{c}\text { Cooperative } \\
(0.403)\end{array}$ & $\begin{array}{c}\text { Cooperative } \\
(0.760)\end{array}$ \\
\hline
\end{tabular}

Note: coefficient values in brackets.

Tab. 2. Cooperative/competitive relationships among the largest 'major' Western Mediterranean ports for the transit category during the period of $2001-2015$

\begin{tabular}{|c|c|c|c|c|c|c|}
\hline & Barcelona & Civitavecchia & Palma de Mallorca & Marseille & Savona & Genoa \\
\hline Barcelona & & $\begin{array}{c}\text { Cooperative } \\
(0.046)\end{array}$ & $\begin{array}{c}\text { Cooperative } \\
(0.291)\end{array}$ & $\begin{array}{c}\text { Cooperative } \\
(0.079)\end{array}$ & $\frac{\text { Competitive }}{(-0.405)}$ & $\begin{array}{c}\text { Cooperative } \\
(0.305)\end{array}$ \\
\hline Palma de Mallorca & $\begin{array}{c}\text { Cooperative } \\
(0.456)\end{array}$ & $\frac{\text { Competitive }}{(-0.333)}$ & & $\begin{array}{c}\text { Cooperative } \\
(0.802)\end{array}$ & $\begin{array}{c}\text { Cooperative } \\
(0.216)\end{array}$ & $\begin{array}{c}\text { Cooperative } \\
(0.168)\end{array}$ \\
\hline
\end{tabular}

Note: coefficient values in brackets.

Civitavecchia has high degree of cooperation with other ports in terms of homeport traffic; however, the cooperation degree is slightly lower for port of call traffic. Thus, the positive development of cruise traffic in the other ports has a positive effect on Civitavecchia. This is the main port of call and the third homeport among the six ports of analysis, with a market share of $29.9 \%$ and $16.6 \%$, respectively, during 2001-2015. The high tourism attractiveness of the 'must-see' destination of Rome generates $65.4 \%$ of cruise traffic in Civitavecchia as transit traffic. Thus, it has significant bargaining power in concentrating itineraries in its berths, mainly as transit calls. Moreover, the competitive relationship with Marseille can be related with the high share of transit traffic in the two ports: Marseille has $71.1 \%$ transit traffic. Both ports have the highest shares of transit traffic. Genoa is the geographically closest port under analysis with respect to Civitavecchia (205 nautical miles); therefore, the competitive relationship obtained can be related to this geography factor.

Palma de Mallorca shows a high degree of cooperation in transit traffic, which is slightly lower in terms of homeport

\section{CONCLUSIONS}

The dynamism of the cruise industry requires that cruise lines seek new ports to design new itineraries and meet demand. The increased supply of itineraries attempts to create differentiated products based on ports that comprise the itinerary. The design of new itineraries is always performed with the idea that the cruise industry sells itineraries rather than single ports/destinations. The Western Mediterranean is a pole of attraction for cruise itineraries that are associated with its tourist attractions, which has allowed a greater number of ports to host cruise ships. The size classification proposed in this paper reveals the significant heterogeneity of cruise ports in the Western Mediterranean based on the passenger movements recorded.

'Major' ports grew at the expense of 'medium' and 'small' ports during the period of 2001-2015. 'Major' ports thus show hierarchical dominance over the 'medium' and 'small' categories. The results of the shift-share analysis highlight that 
the process of gain or loss does not seek to destroy market participants but rather reduce their market shares because ports need each other to generate itineraries. Among the causes of the most important losses are geopolitical instability events and a lack of adequate facilities for the new generation of large cruise ships and mega-cruise ships that have been put into service in recent years. Mega-cruise ships have had an increasing presence in the cruise fleet. If the cruise facilities of ports are not adapted to the new large sizes, their cruise business strategies should be reoriented to smaller sizes, which are primarily associated with luxury, upper premium and premium segments rather than contemporary segments. The positive shifts have the intervention of a private terminal operator in several ports as a common element in recent years. Moreover, in some cases, the private terminal operator is a cruise line or a cruise line partnership, indicating a process of vertical integration in the cruise industry. Furthermore, in 2012 , losses in 15 of the 29 ports analysed can be attributed to the effects of the Costa Concordia ship disaster.

The concentration in the sample of 29 ports during the first 15 years of the 21st century has remained stable over time, according to the changes in the values of HHI and G. The concentration analysis allows us to determine that the gains of 'major' ports is not so high (8.5\% of the average total passenger movements of this port group during 2000-2015) as to vary the concentration. The concentration does not vary significantly because ports need one another. The central element around which the cruise industry is structured, the itineraries, has led to complex cooperative/competitive relationships between ports. These relationships can be seen at the inter- or intra-itinerary level. The results obtained show cooperative relationships between the three largest cruise ports of the 'major' group. Therefore, the largest 'major' ports perceive other ports as collaborators based on the principle that the element marketed by the cruise industry is the itinerary.

\section{BIBLIOGRAPHY}

1. Bagis, O.; Dooms, M.: Turkey's potential on becoming a cruise hub for the East Mediterranean Region: The case of Istanbul. Research in Transportation Business \& Management, vol. 13, pp. 6-15, 2014.

2. Branderburger, A.; Nalebuff, B.: Co-opetition. Doubleday, New York 1996.

3. Castillo-Manzano, J.I.; Fageda, X.; Gonzalez-Laxe, F.: An analysis of the determinants of cruise traffic: An empirical application to the Spanish port system. Transportation Research Part E, vol. 66, pp. 115-125, 2014.

4. CLIA (Cruise Lines International Association): 2016 cruise industry outlook. CLIA, Washington 2016.

5. Cruise Market Watch: Growth of the Cruise Line Industry [online]. Available from: http://www.cruisemarketwatch. com/growth/. [Accessed 31 May 2016].
6. Esteve-Perez, J.; Garcia-Sanchez, A.: Cruise market: Stakeholders and the role of ports and tourist hinterlands. Maritime Economics \& Logistics, vol. 17(3), pp. 371-388, 2015.

7. Esteve-Perez, J.; Garcia-Sanchez, A.: La industria de cruceros: características, agentes y sus funciones. Fundación Valenciaport, Valencia 2015.

8. Hamel, G.; Doz, Y; Prahalad, C.: Collaborate with your competitors-and win. Harvard Business Review, vol. 67, pp. 133-139, 1989.

9. Lau, Y.; Tam, K.; Ng, A.K.Y.; Pallis, A.A.: Cruise terminals site selection process: An institutional analysis of the Kai Tak Cruise Terminal in Hong Kong. Research in Transportation Business \& Management, vol. 13, pp. 16-23, 2014.

10. Lekakou, M.B.; Pallis, A.A.; Vaggelas, G.K.: An analysis of cruise industry's selection criteria. Paper presented at the International Association of Maritime Economists Annual Conference, June 24-26. Copenhagen, Denmark, 2009.

11. Marti, B.E.: Geography and the cruise ship port selection process. Maritime Policy \& Management, vol. 17(3), pp. 157-164, 1990.

12. McCalla, R.J.: An Investigation into Site and Situation: Cruise Ship Ports. Tijdschrift voor Economische en Sociale Geografie, vol. 89(1), pp. 44-55, 1998.

13. MedCruise: The New Medcruise Statistic Report. MedCruise, Barcelona 2011.

14. MedCruise: Cruise activities in MedCruise ports: Statistics 2013. MedCruise, Piraeus 2014.

15. MedCruise: Cruise activities in MedCruise ports: Statistics 2014. MedCruise, Piraeus 2015.

16. MedCruise: Cruise activities in MedCruise ports: Statistics 2015. MedCruise, Piraeus 2016.

17. MedCruise: French Riviera Ports-Ports facts [online]. Available from: http://www.medcruise.com/port/488/ french-riviera-ports/information. [Accesed 27 June 2016].

18. Notteboom, T.E.: Concentration and load centre development in the European container port system. Journal of Transport Geography, vol. 5(2), pp. 99-115, 1997.

19. Pallis, A.A.: Cruise Shipping and Urban Development: State of the Art of the Industry and Cruise Ports. International Transport Forum, Paris 2015. 
20. Pallis, A.A.; Arapi, K.P.: A Multi-Port Cruise Region: Dynamics and Hierarchies in the Med. Tourismos, vol. 11(2), pp. 168-201, 2016.

21. Rodrigue, J.P.; Notteboom, T.: The geography of cruises: Itineraries, not destinations. Applied Geography, vol. 38, pp. 31-42, 2013.

22. Rodrigue, J.P.; Comtois, C.; Slack, B.: The geography of transport systems (3rd ed.). Routledge, Abingdon 2013.

23. Song, D.W.: Port co-opetition in concept and practice. Maritime Policy and Management, vol. 30(1), pp. 29-44, 2003.

24. Song, D.W.: Regional container port competition and co-operation: the case of Hong Kong and South China. Journal of Transport Geography, vol. 10, pp. 99-110, 2002.

25. Twrdy, E.; Batista, M.: Competition between container ports in the Northern Adriatic. International Journal for Traffic and Transport Engineering, vol. 4(4), pp. 363-371, 2014.

26. UNCTAD (United Nations Conference on Trade And Development): Review of Maritime Transport 2015. UNCTAD, Geneva 2015.

27. Wang, G.W.Y.; Pallis, A.A.; Notteboom, T.E.: Incentives in cruise terminal concession contracts. Research in Transportation Business \& Management, vol. 13, pp. 36-42, 2014.

28. Wilson, P.; Chern, T.S.; Ping, T.S.; Robinson, E.: A Dynamic Shift-Share Analysis of the Electronics Export Market 19882001: Can the NIEs Compete with China?. SCAPE Working Paper Series, Paper No. 2005/07, May 2005.

\section{CONTACT WITH THE AUTHORS}

Jeronimo Esteve-Perez

e-mail: jeronimo.esteve@upct.es

Universidad Politécnica de Cartagena Department of Naval Technology

Paseo Alfonso XIII, 52, 30203 Cartagena

\section{SPAIN}

Antonio Garcia-Sanchez e-mail:a.garciasanchez@upct.es Universidad Politécnica de Cartagena

Department of Economics

Calle Real, 3, 30201 Cartagena

SPAIN 